\title{
Performance of Solar Module with Presence of Two Types of Reflectors in Concentrator System
}

\author{
Naseer K. Kasim ${ }^{1}$, Ahmed F. Atwan ${ }^{2}$, Fadhil Mahmood Oleiwi ${ }^{3}$ \\ ${ }^{1}$ Alhussein University College. \& Ministry of electricity- Training and Energy Research Office. \\ ${ }^{2}$ Mustansiriyah University, College of Education, Physics Department. \\ ${ }^{3}$ Ministry of education, Iraq. \\ irss2004@yahoo.com,ahmedfarhan51@yahoo.com,fadhilphy@yahoo.com
}

\begin{abstract}
Any work to improve the performance of the solar modules could add to their economic competitiveness against fossil fuels. In the present work the performance of $P V$ solar module was improved by using V-Trough concentrator system (CPV) which moved by two axis tracking system. The concentrator consists of two flat reflectors of area $2 \mathrm{~m}^{2}$ for each one with geometric concentration ratio of $2 X$. To optimize the performance of the $V$-Trough CPV systems, two types of reflector material, Aluminum and mirror (glass coated by silver nitrate) were used. The results indicated that the temperature of $P V$ reference module was higher than the ambient temperature by $27^{\circ} \mathrm{C}$ but there is too small difference in temperature between the tracking $P V$ module with the reference which ranged to $2^{\circ} C$, while the temperature of the CPV system was higher than reference by $37^{\circ} \mathrm{C}$. The temperature of the PV module under mirror reflectors was lower than module combined with Aluminum reflectors by $3^{\circ} \mathrm{C}$. As a result of arising of the temperature of $C P V$ system in compare with $P V$ reference module, the open circuit voltage was droop by $0.7 \mathrm{~V}, 0.5 \mathrm{~V}$ for $P V$ module under mirror and Aluminum reflectors respectively. The reflectors increased the short circuit current values by 2.1 A, 2.6 A for PV module combined with mirror and Aluminum reflectors respectively. Accordingly the performance (as an average daily gain of output power) of the PV solar module was improved by using V-Trough CPV system, 44\%, 34\% by using Aluminum and mirror reflectors respectively.

Index Terms - Aluminum reflector, mirror reflector, Solar tracking system. V-Trough concentrator.
\end{abstract}

\section{INTRODUCTION}

PV Solar module is a devices using to convert the solar irradiance to electric energy. The improvement of the performance of PV Solar module had been done by two ways, new materials' and new techniques. Concentrator solar irradiance on PV surface by reflectors is considered one of the promised techniques and considered as the third generation of PV solar technology. PV panel have a little operative cost, limited output powers and high capital costs, possible way to reduce these principal costs and increase output power is added an optical systems (reflectors) which increase the incident solar irradiance on the solar panel surface [1]. In order to increase the attractiveness of PV energy, use solar photovoltaic concentrators modules (CPV), introducing tracking system, reduce mismatch losses of module and reduce temperature of module by cooling considered [2]. Kasim et al studied fixed V-Trough CPV system in Baghdad climate who found that the performance of this system is increased by $47 \%$ in compare with the reference PV solar module, and the temperature of the CPV system increased only $10^{\circ} \mathrm{C}$ in compare with the same reference [3]. Torres et al focused on the redesign of CPV collector reflector which produces by the Swedish company together with detailed analysis based on the annual evaluation of the solar irradiance in the collector. An open source ray tracing cod (soltrace) is used to achieve the modeling the optical system in CPV applications [4 ]. Ronnelid et al 
considered the act of photovoltaic modules with V-trough booster reflectors with different length and tilts for Swedish conditions. They stated that a flat stationary booster reflector can increase the annual output of the module in the order of 20-25 percent [5]. Different materials were used to fabricate solar reflectors to improve the performance of solar module, and the best reflector (could concentrate highest amount of radiation) was selected for the uses. Experiments were executed on aluminum; stainless steel, and chrome film reflectors to specify the most efficient type of reflector that assist to producing highest module output power and less amount of excess heat. The results showed that, chrome reflector assist to generate $27.65 \%$ additional module output power against aluminum foil and $34.05 \%$ more output power against stainless steel reflectors respectively [6]. Kennedy et al identify new, cost effective advanced reflector materials that are solid with weathering, the glass mirrors may meet the 10-year lifetime goals based on accelerated exposure testing [7]. The stainless steel and aluminum foil reflectors can increase the output power of polycrystalline solar module around $8.5 \%-14 \%$. The aluminum foil reflector and water film concurrently improved the performance of PV solar module about $50 \%$ in power generation [8]. Jones et al tested a number of reflector samples, Durability, degradation, and failure patterns, test results may be used to derive insight into failure mechanisms, associated physical parameters, service lifetimes, and uncertain in performance [9]. A theoretical and experimentally studies were done to estimate the effect of one and two reflectors in V-trough concentrator system on the amount of concentrated radiation ratio on solar PV module. It was observed that, there was, at noon, increasing in insolation by $61 \%$ and $120 \%$ respectively [10]. Present work focuses on the performance optimization of V-Trough CPV system by using two cheapest Aluminum and mirror reflectors to reduce the cost of solar electricity in compare with conventional PV solar system as well as to reduce the mismatch losses of the PV modules. One of the main targets of this project is supporting our national grid, especially, in summer peak time. The introducing CPV systems in different consumption sectors treat the location with limited area, especially, most of these consumption sectors suffering from shortage of supplying electricity for a long time.

\section{TROUGH PV SOLAR CONCENTRATOR}

V-trough concentrator geometry is defined by two factors: the Geometric concentration ratio and the vertex angle $(\Psi)$ (the angle between reflector and the column on PV), as shown in Fig.1.

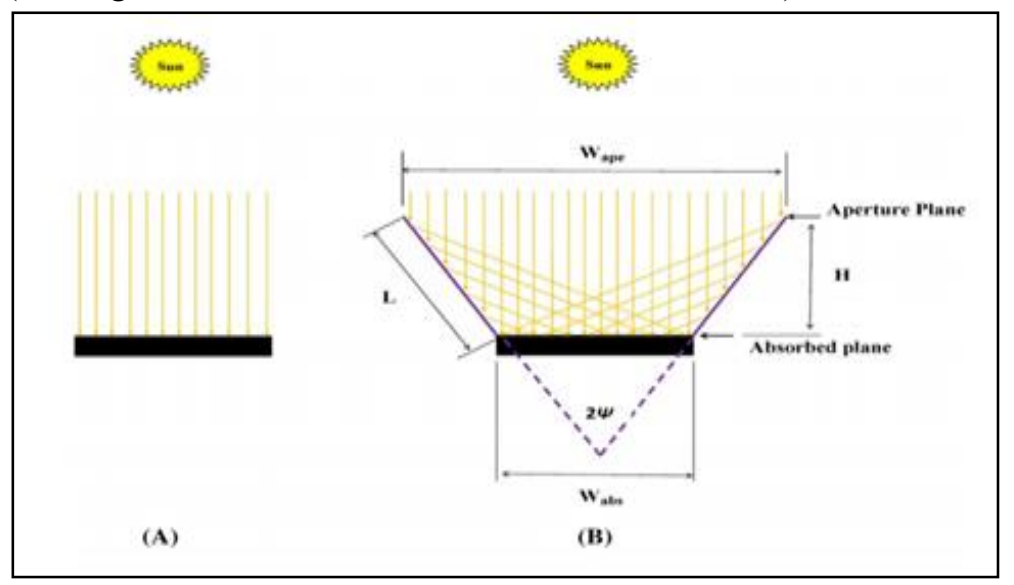

Fig.1 . A- PV module, B- V-PV module [12]

The geometric concentration ratio is the ratio between the area of aperture plane (A) and area of the PV surface plane a which can be expressed by [11]:

$$
C=\frac{A}{a}=\frac{W_{a p e}}{W_{a b s}}
$$


Where the Wape is the aperture width and Wabs is the PV module width. The geometric concentration ratio in the system at vertex angle equal $30 \mathrm{o}$ is two sun $(2 \mathrm{X})$. V-trough concentrator's are reflecting surfaces which increase the incident solar irradiance to increase the energy output of the PV module. The total solar radiation Gtot on the PV module surface is the sum of the direct radiation on module surface $G_{b}$, the sky-diffuse radiation $G_{d}$, the albedo radiation $G_{g}$, the reflected radiation from lower and upper reflector which reaches the module surface are $\mathrm{G}_{\mathrm{r} 1}$ and $\mathrm{G}_{\mathrm{r} 2}$ [13].

$$
G_{t o t}=G_{b}+G_{d}+G_{g}+G_{r 1}+G_{r 2}
$$

The short circuit current (Is) is proportional to the solar irradiance (Gtot) and the open circuit voltage (Voc) is proportional to the solar cell temperature (Tc). The practical short circuit current and practical open circuit voltage are given as [14].

$$
\begin{gathered}
I_{s c}(G)=I_{S c}\left(a t^{1 \frac{k w}{m 2}}\right) * G\left(\operatorname{in}^{1 \frac{k w}{m 2}}\right) \\
V_{o c}\left(T_{C}\right)=V_{o c}-0.0023 \times \text { number of cells } \times\left(T_{C}-25\right)
\end{gathered}
$$

The cell temperature $(\mathrm{Tc})$ is [13]:

$$
T_{C}=T_{a}+\frac{N O C T-20}{0.8} *\left(9.5 /\left(5.7+3.8 * V_{W}\right.\right.
$$

Where (NOCT) is normal operating cell temperature (usually between 42 and $46{ }^{\circ} \mathrm{C}$ ), and Ta is ambient temperature and $(\mathrm{Vw})$ is wind spead [14]. The output power of the PV module can be estimated by the following equation [14].

$$
P=I_{S C} * V_{O C}
$$

\section{DESCRIPTION OF CPV SYSTEM:}

CPV system involves poly-crystalline solar modules and V-trough concentrators with two types of reflector materials, Aluminum sheets and glass mirror (Fig. 2). This system supplied with two dimensions tracing system. A single PV module without concentrator system was used as a reference. PV module characteristics are listed in TABLE 1. All the solar PV modules, those are submitted to the study, are with the same characteristics.
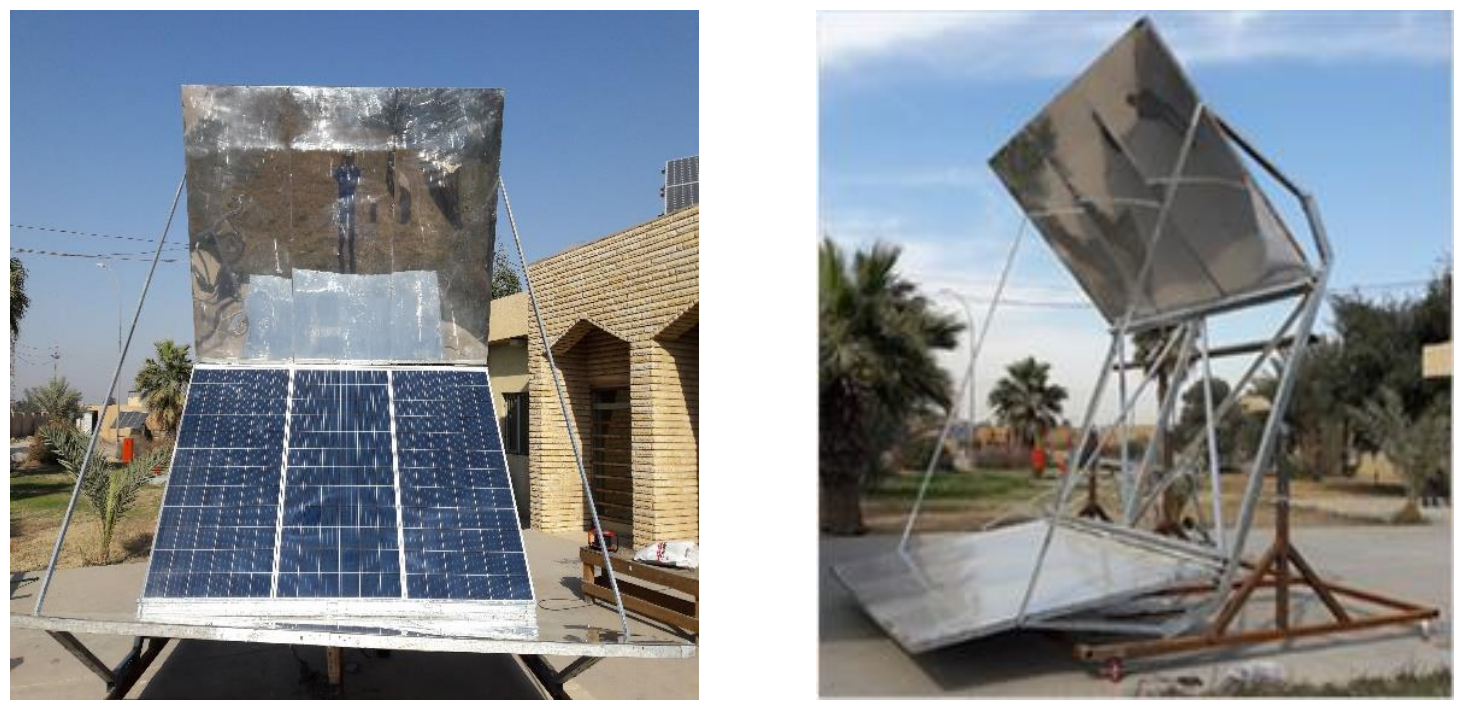

Fig.2 . V-Trough CPV system. 
TABLE 1. SPECIFICATIONS OF POLY-CRYSTALLINE SOLAR PV

\begin{tabular}{cccc}
\hline Parameter & Value & Parameter & Value \\
\hline Dimensio & $1958 * 992 * 50 \mathrm{~mm}$ & $\mathrm{p}_{\max }$ & $330 \mathrm{~W}$ \\
Weight & $27 \mathrm{~kg}$ & Temperature coefficient $\mathrm{V}_{\mathrm{OC}}$ & $-0.31 \mathrm{~V} /{ }^{\circ} \mathrm{C}$ \\
NoOf Cells & 72 in series & Temperature coefficient $\mathrm{I}_{\mathrm{sc}}$ & $0.41 \mathrm{~mA} /{ }^{\circ} \mathrm{C}$ \\
$\mathrm{ISc}_{\mathrm{Sc}}$ & $9.28 \mathrm{~A}$ & Temperature coefficient $\mathrm{P}_{\max }$ & $-0.4 \% /{ }^{\circ} \mathrm{C}$ \\
$\mathrm{V}_{\mathrm{OC}}$ & $45.9 \mathrm{~V}$ & Module efficiency & $17 \%$ \\
$\mathrm{I}_{\mathrm{pm}}$ & $8.85 \mathrm{~A}$ & NOCT & $45{ }^{\circ} \mathrm{C}$ \\
$\mathrm{V}_{\mathrm{pm}}$ & $37.3 \mathrm{~V}$ & Type of cell & $\mathrm{Pc}-\mathrm{si}$ \\
\hline
\end{tabular}

The study was done in Al-Zwraa company, from (9) Am to (13) Pm in August / 2018. The temperature of ambient (Ta), temperature of fixed solar reference PV module (Tpvr), temperature of tracker reference solar PV module (Tpvrt), temperature of concentrated solar PV module with aluminum reflectors (Tcpv-AL), temperature of concentrated solar PV module with glass mirror reflectors (Tcpv-M), short circuit current (Isc) and open circuit voltage (Voc), with or without reflectors were measured and recorded. The concentration ratio of the system at vertex angle equal to $30 \mathrm{o}$ was 2 suns, and the tilt angle of reference solar PV module was $34^{\circ}$.

\section{RESULTS AND DISCUSSION:}

In the present work the ambient temperature, solar PV module temperature with and without concentrator system, and temperatures of Aluminum reflector (T-ALr) and mirror reflector (T-Mr) were recorded and plotted as shown in Fig. 3 and Fig. 4.

The temperature measurements of the two types of reflectors indicated to temperature arising of the mirror reflector (glass substrate coated by silver nitrate on backside of the substrate) by $7 \mathrm{oC}$ in compare with Aluminum reflector due to the reflection of incident solar radiation on the mirror reflector occurred from the backside of the substrate reflector and the solar radiation passes back and forth through the substrate material (not perfect optical glass quality which leads to low reflectivity), but in the second reflector (Aluminum) the reflection occurred from the front side of the reflector (there is no transmission losses) as shown in the figure 3. The sharp drop in temperature of the two types of reflectors after 11:30 O'clock was due to increasing the wind speed from $1 \mathrm{~m} / \mathrm{s}$ to $4 \mathrm{~m} / \mathrm{s}$. This result is in good match with the result mentioned in reference [15].

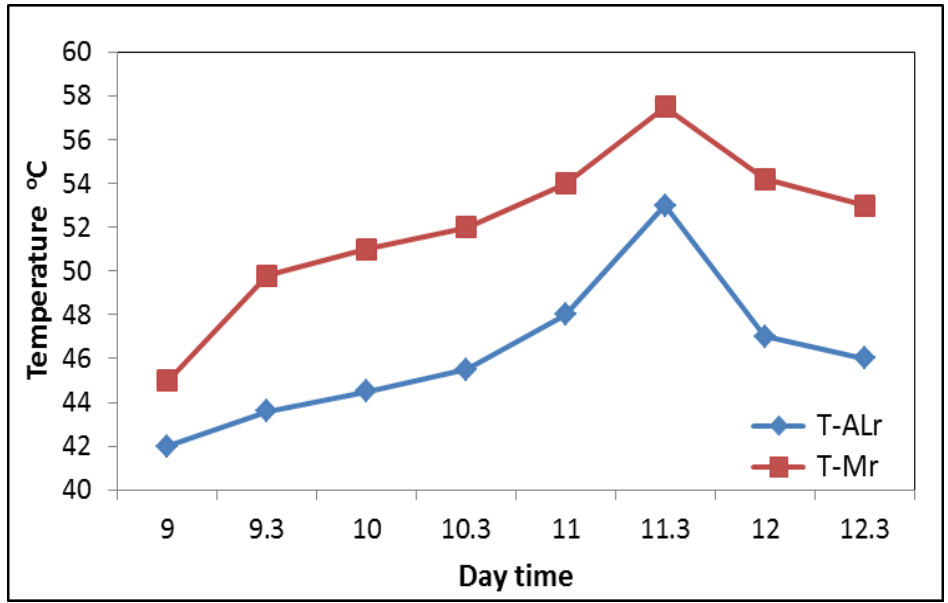

FIG. 3. REFLECTORS TEMPERATURE VERSUS DAY TIME 


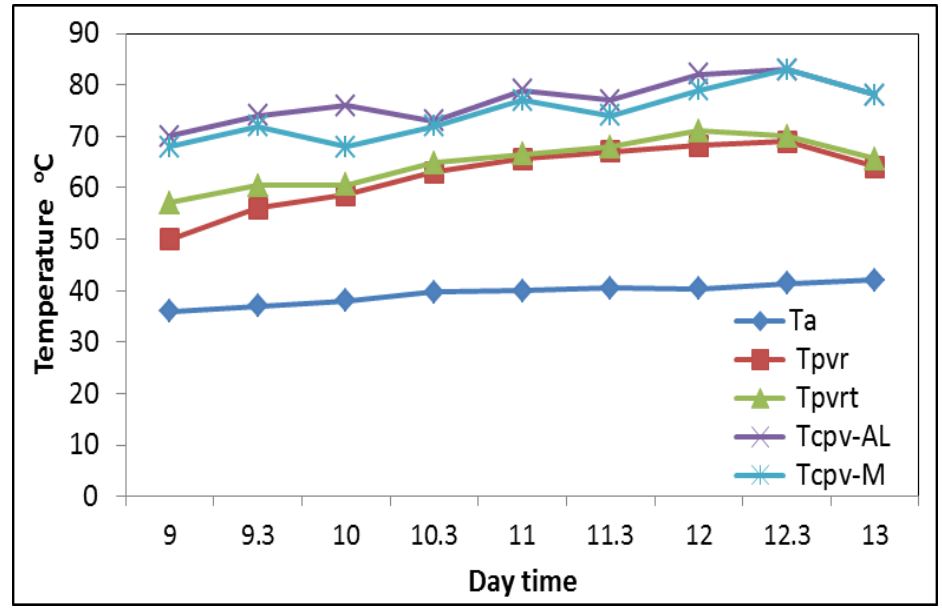

Fig. 4. VARIATION OF AMBIENT AND MODULE TEMPERATURES WITH DAY TIME

Fig. 4 indicated that the temperature of PV reference module was higher than the ambient temperature by $27 \mathrm{oC}$ but there is too small difference in temperature between the tracking PV module and the fixed reference module which ranged to $20 \mathrm{C}$, while the temperature of the CPV system was higher than reference by $37 \mathrm{oC}$. The temperature of the PV module combined with mirror reflectors was lower than module combined with Aluminum reflectors by $3 \mathrm{oC}$. As a result of arising of the temperature of CPV system in compare with PV reference module, the open circuit voltage was droop by $0.7 \mathrm{~V}, 0.5 \mathrm{~V}$ for PV module under mirror and Aluminum reflectors respectively. The reflectors increased the short circuit current values by 2.1 A, 2.6 A for PV module combined with mirror and Aluminum reflectors respectively. Accordingly the performance (as an average daily gain of output power) of the PV solar module was improved by using V-Trough CPV system, $44 \%, 34 \%$ by using Aluminum and mirror reflectors respectively.

It is known that the increase in module temperature leads to drop in its open circuit voltage (Voc). This fact is demonstrated in Fig. 5, in which the module with highest temperature has the most drops in Voc. While the short circuit current (Isc) is not affected significantly by temperature but it arises with increase the amount of incident radiation (Irradiance). This case can be achieved by reflectors as shown in Fig. 6

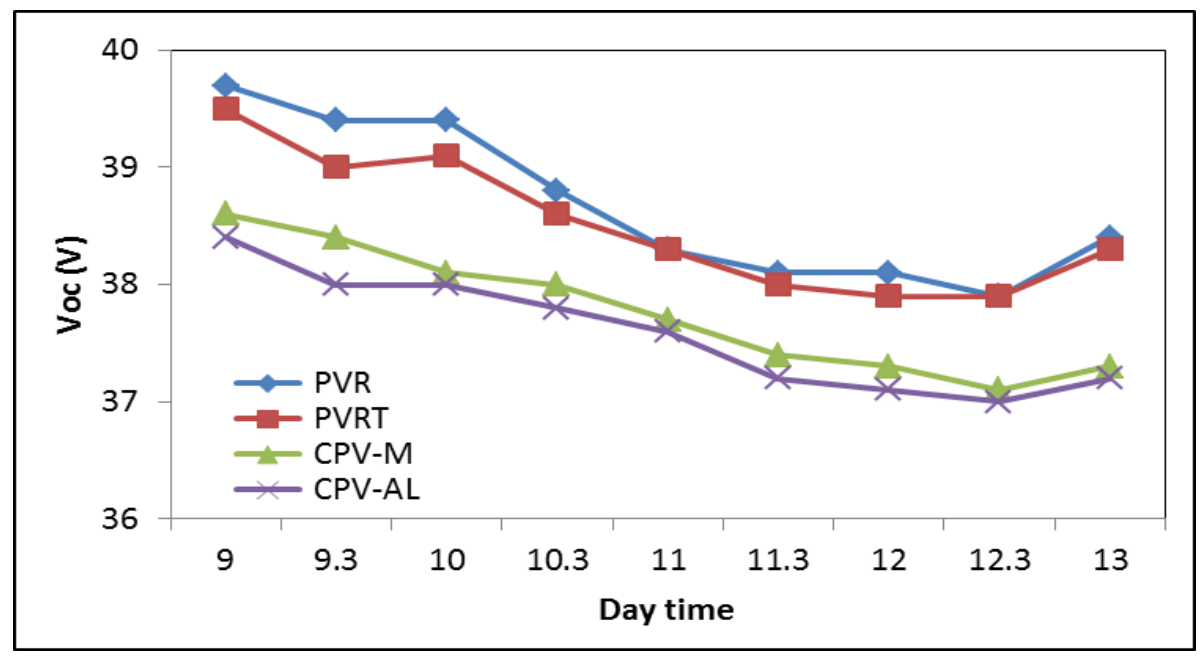

Fig. 5. PV SOLAR MODULE OPEN CIRCUIT VOLTAGE WITH DAY TIME. 


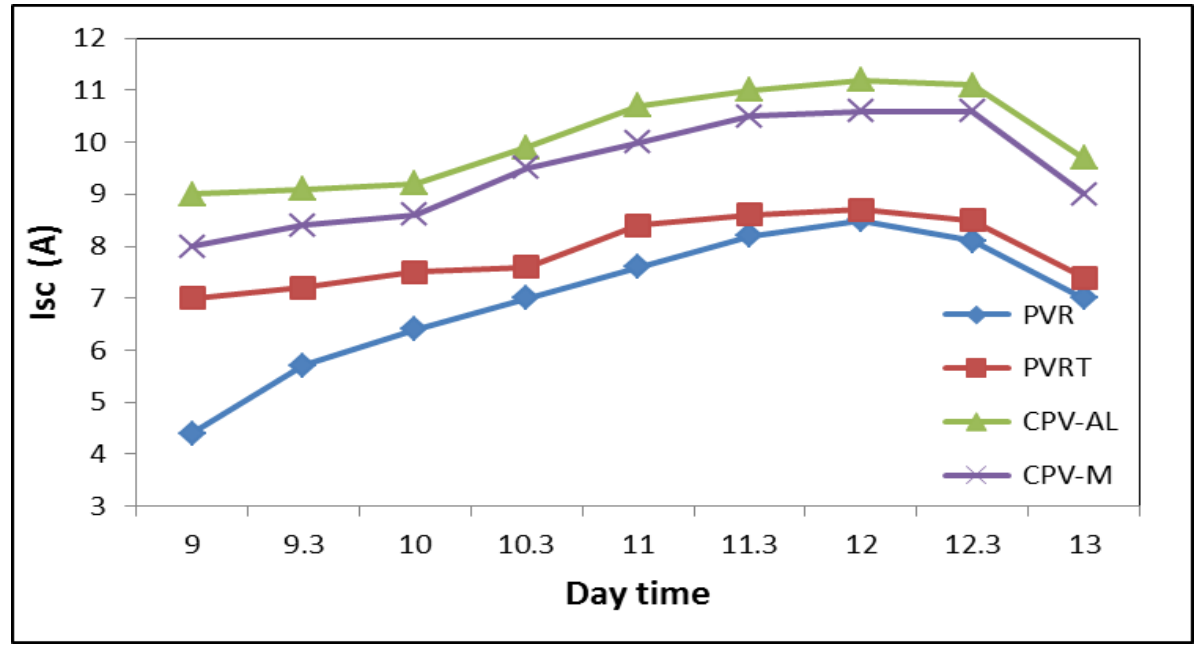

FIG. 6. PV SOLAR MODULE SHORT CIRCUIT CURRENT WITH DAY TIME.

Fig. 6 shows that the module with Aluminum reflector (CPV-AL) produces more current than that with mirror reflector (CPV-M). From the above results it can be seen that, with presence of concentrator system, the increase in current is more effective than drop in voltage. This fact is materialized in Fig.7.

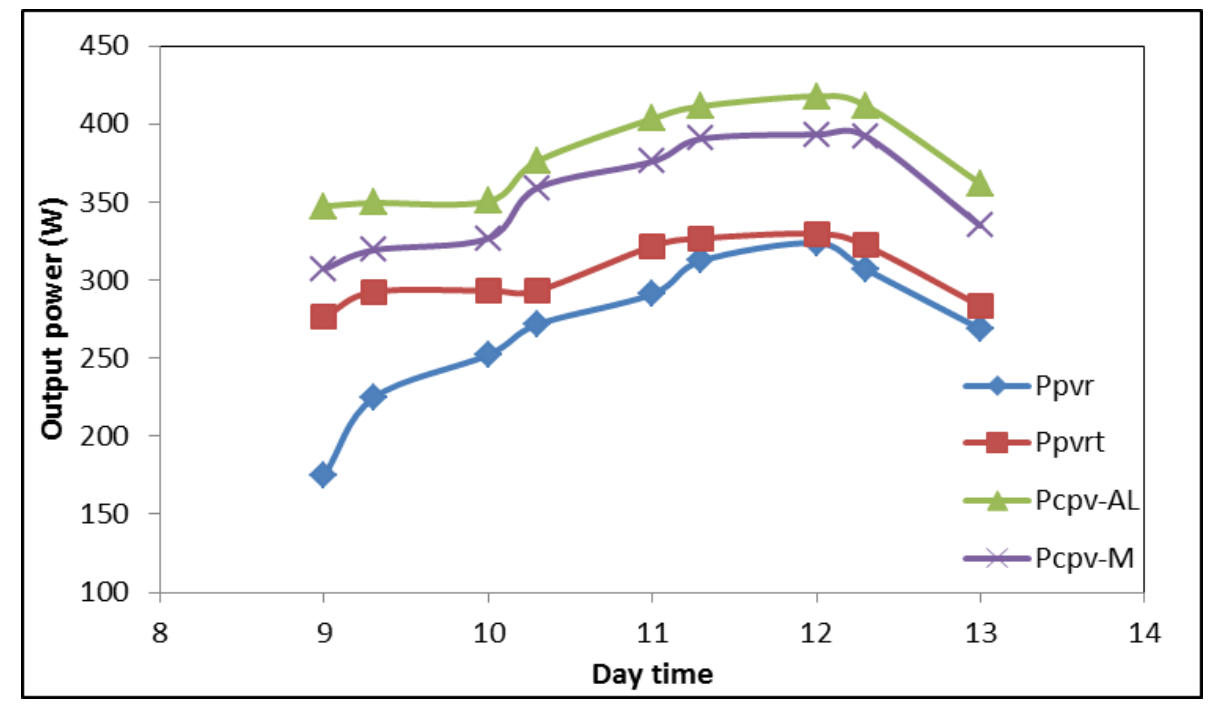

Fig. 7. OUTPUT POWER WITH DAY TIME.

Fig.7 shows, explicitly, that the module with Aluminum reflectors (Pcpv-AL) more efficient than that with mirror reflectors (Pcpv-M). This figure, also, shows the tracking system adding gain in output power with different ratio along day time (see Fig. 8). 


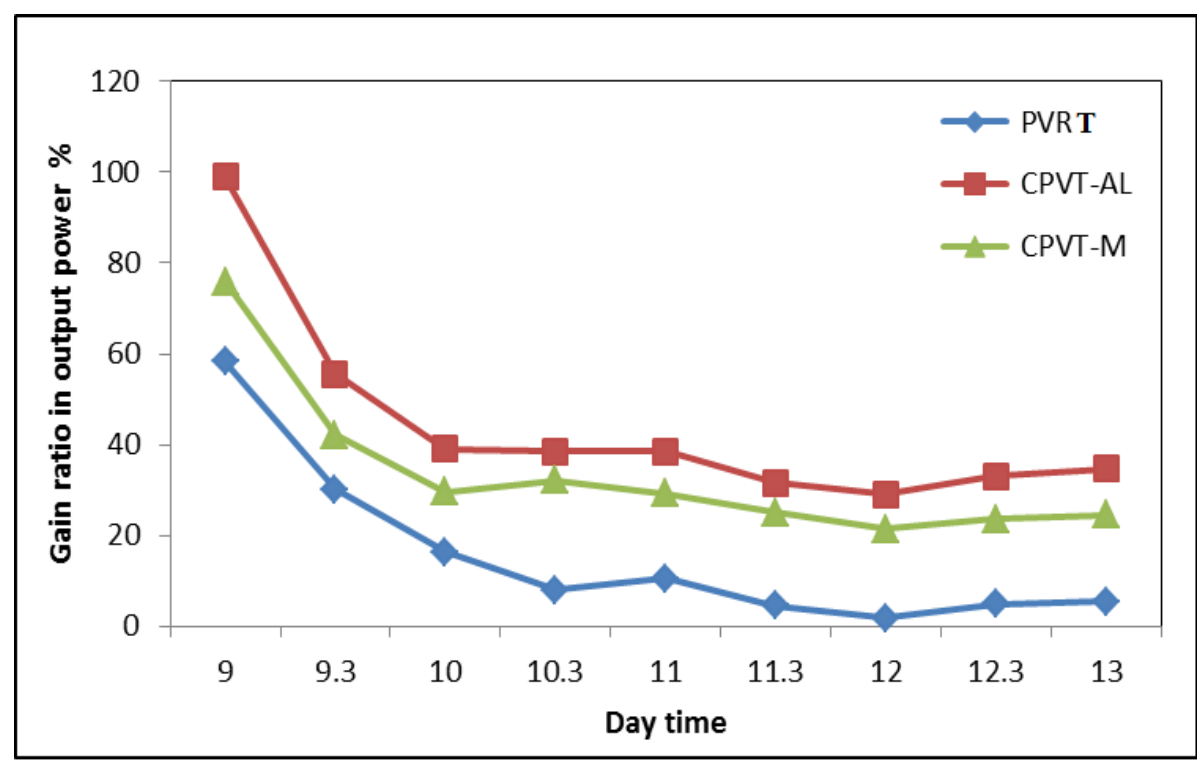

FIG. 8. GAIN RATIO IN OUTPUT POWER CPV MODULES IN COMPARE WITH FIXED REFERENCE MODULE.

The gain ratio has highest values at morning and afternoon and has lowest values at mid noon in compare with fixed reference module.

Finally, the cost of the two types of reflectors did not exceeded than ten percent from the total cost of the system

\section{CONCLUSION}

Present work leads us to conclude that, the characteristics of reflector materials play an important role in improve the performance of PV solar module and generate access output power, and according to reflection efficiency, lightweight, safety, durability, and cost considerations, the Aluminum reflectors is considered more efficient than glass mirror reflectors. It can be, also, concluded that there is no big difference in the temperature of the two types of the reflectors, as well as the effect of increasing the current as a result from the increasing solar irradiance is more effective in increasing in power gain. Finally, the CPV technique is promised technology and more economic feasible, especially, when it use with high efficient PV solar module.

\section{REFERENCES}

[1] Swanson R.(2000), "The promise of concentrators”, Prog Photovoltaics: Res APP 8:93-111.,ISBN: 978-2003.

[2] A. Hanel and M. S. Imamura, (1992), Improvement of PV array performance. Proc.l th E.C. Photovoltaic Solar Energy Conf., Montreux, Switzerland, ed. L. Guimaraes et al.

[3] Kasim, N. K., Atwan, A. F., \& Eliewi, F. M. (2018, May). Improve the performance of solar modules by reflectors. In Journal of Physics: Conference Series (Vol. 1032, No. 1, p. 012031). IOP Publishing.

[4] Torres, J., Fernandes, C., Gomes, J., Luc, B., Carine, G., Olsson, O. and Branco, P., 2018. Effect of reflector geometry in the annual received radiation of low concentration photovoltaic systems. Energies, 11(7), p.1878.

[5] Ronnelid, M., Karlsson, B., Krohn, P. \& Wennerberg. J. (2000). Booster reflectors for PV modules in Sweden. Progress in Photovoltaics: Research and Applications, Vol. 8, pp. 279-291.

[6] Rizk, J., \& Nagrial, M. H., (2009)," Impact of reflectors on solar energy systems", International Journal of Electrical, Computer, Energetic, Electronic and Communication Engineering Vol:2, No:5, 2008

[7] Kennedy, C., Terwilliger, K. and Milbourne, M., 2005. Development and testing of solar reflectors (No. NREL/CP-52036582). National Renewable Energy Lab.(NREL), Golden, CO (United States).

[8] Tabaei, H., and M. Ameri, (2015), " Improving the effectiveness of a photovoltaic water pumping system by using booster refiector and cooling array surface by a film of." Iranian Journal of Science and Technology. Transactions of Mechanical Engineering 39.M1: 51. 
[9] Jones, W., Elmore, R., Lee, J. and Kennedy, C., 2011. Step-Stress Accelerated Degradation Testing for Solar Reflectors: Preprint (No. NREL/CP-2C00-52624). National Renewable Energy Lab.(NREL), Golden, CO (United States).

[10] Alaa A. shneishil, (2016), "Desighn and performance Analysisof a v-trough photovoltaic concentrator", Dyala journal for pure science, vol.13, No.1-3,pp.134-116, ISSN.8373222/25189255.

[11] Fraidenraich, N., (1992), "Analytic solutions for the optical properties of V trough concentrators". Appl. Opt. 31 (1), 131-139.

[12] Al -Shohani, W. A., Al -Dadah, R., Mahmoud, S., \& Algareu, A., (2016), "Performance of a V-trough photovoltaic system ”. In Renewable Energy Research and Applications (ICRERA), 2016 IEEE International Conference , pp. 946951.

[13] Duffie, J. A., \& Beckman, W. A. (2013). Solar engineering of thermal processes. John Wiley \& Sons.

[14] Markvart, T.: Solar Electricity. Wiley, Chichester (2001).

[15] Sangani, C.S. and Solanki, C.S., 2007. Experimental evaluation of V-trough (2 suns) PV concentrator system using commercial PV modules. Solar Energy Materials and Solar Cells, 91(6), pp.453-459 